\title{
CHMSC-BFAR Community Based Environmental Conservation
}

\author{
Elenuel T. Genova, Mario N. Abeto and Noel N. Lebrilla
}

\begin{abstract}
In 2012, The Philippine National Aquasilviculture Project (PNAP) was forged and formally launched by the Department of Agriculture Bureau of Fisheries and Aquatic Resources (DABFAR). To implement the PNAP, a Memorandum of Agreement (MOA) was executed by and between BFAR and the Commission on Higher Education (CHED) on December 16, 2011. The study was conducted to assess the status and development of the PNAP program implemented in Southern Negros, at four (4) Municipalities and two (2) Cities. The BFAR downloaded a total fund amounting Php 10,148,812.50 for the four (4) phases of the program wherein, the Php $\mathbf{6 , 4 2 2 , 7 6 2 . 5}$ was spent for resource rehabilitation (mangrove planting); Php 845,000.00 for Aquasilviculture; Php 1,140,000.00 for Multi-species hatchery and Php 1,741,050.00 for administrative costs. The total paid mangrove propagules planted in Southern Negros was 978,000 with $30 \%$ buffer with a total of 1,144,260 survived propagules planted in 130.4 hectares of coastal land in Southern Negros and commensurate 673 direct beneficiaries. The 274 fisherfolk beneficiaries augmented income from Aquasilviculture project while a total of 1,284 berried wild bluecrab which estimated to produce up to 2 million eggs have been reared in Multi-species hatchery. A conservative estimate of $1 \%$ survival in natural habitat under natural conditions represented the contribution of the project for the beleaguered bluecrab capture fisheries. The beneficiaries really appreciate the efforts made by CHMSC-Binalbagan as program implementer based on their responses on the given important factors of service delivery to the community.
\end{abstract}

Keywords:- PNAP, Mangrove Rehabilitation, Aquasilviculture, Multi-species Hatchery.

\section{INTRODUCTION}

Mangroves of the southern Negros Occidental, Philippines harbors diverse species of flora and fauna with its 21 species exclusive true mangrove species recorded from the previous survey conducted by the CHMSC COF RDU. However, just like the plight of mangroves in all regions of the world, southern Negros Occidental mangroves, in course of time, also experience tangible shrinkage of habitat as well as population of species. Worldwide, the depletion of the species is mainly due to severe biotic pressure coupled with other coastal dynamic changes and ecological changes. Mangrove forests are composed of several species having great economic potentialities, which inspire people to exploit the mangrove forests in an unplanned manner to meet their needs (Panda, Mardaraj, Subudhi, and Sahu, 2013). These anthropogenic and natural processes pressures call for immediate conservation of the mangrove forests - the need of the hour.

Realizing these, the Philippine Government through the Bureau of Fisheries and Aquatic Resources (BFAR) now emphasizes over the conservation of mangrove vegetation in almost all regions and provinces of the country. The aims of the community-based mangrove conservation project under the Philippine National Aquasilviculture Program (PNAP) are the restoration, rehabilitation and conservation of the unique and priceless mangrove ecosystems of the coastal regions in the Philippines through large scale mangrove plantations. However, the question on the attitude of the participating peoples' organization (PO) comes into account towards sustaining the project at the termination phase after 5 years of its implementation. While most terminal reports highlights the socio-economic and ecological dimensions of the project, this study attempts to emphasize the psychological dimension in community-based mangrove conservation.

In 2012, The Philippine National Aquasilviculture Project (PNAP) was forged and formally launched by the Department of Agriculture - Bureau of Fisheries and Aquatic Resources (DA-BFAR). To implement the PNAP, a Memorandum of Agreement (MOA) was executed by and between BFAR and the Commission on Higher Education (CHED) on December 16, 2011. The program concept is primarily mangrove resource rehabilitation and livelihood provision to help address climate change, food security and poverty among municipal or artisanal coastal fisher folk.

Carlos Hilado Memerial State College State College - Binalbagan Campus was one of the granted School to implement the program.

\section{$>$ Objective of the Study}

The aim of this study is to assess the status and development of the PNAP program implemented in Southern Negros, at four (4) Municipalities and two (2) Cities. Specifically, this study will:

- Determine the number of Beneficiaries per phase of PNAP mangrove CBC project implemented in Southern Negros Occidental Philippines when grouped according to locality.

- Determine the cost of project per phase of PNAP mangrove $\mathrm{CBC}$ project implemented in Southern 
Negros Occidental Philippines when grouped according to locality.

- Determine the status and development of project per phase of PNAP mangrove CBC project implemented in Southern Negros Occidental Philippines when grouped according to locality.

- Determine the satisfaction of the Beneficiaries for PNAP mangrove CBC project implemented in Southern Negros Occidental Philippines.

\section{$>$ Theoretical Framework}

CBC: Shaping Community's Attitude to Participate and Sustain Action. Community-based conservation has become a major buzzword alongside the terms "participation" and "sustainability." As an emerging strategy, a community-based frame reconciles conservation goals and human needs. In a more specific context, the loss of local institutions in community-based paradigm will provoke natural resource degradation. Clear, the loss of conservation and management systems for common property mangrove resource has been a critical issue to an imperiled resource that resulted to diminished goods and services derived from the ecosystem necessary to support humans.

The idea of community-based conservation is that through community-based activities, local people will benefit, thus will be more likely to support it. The neglect of importance of grounded knowledge to be embedded in the program are too interesting frames to discuss - the psychological factors as program impact being explained in terms of the potential of the communities for selfdefining and self-sustaining activities.

\section{METHODOLOGY}

Research Design

A Descriptive Research design was used to elicit information about the "CHMSC-BFAR COMMUNITY
BASED ENVIRONMENTAL CONSERVATION" in which focuses on the historical data of the project and also measures beneficiary's satisfaction.

According to Librero (1996), a survey research design allows to study "natural occurring phenomena." Furthermore, a researcher collects a data from a part of the population to assess the interrelationship of the variables in his/her study. Survey research is the most efficient method in gathering data that will be used to describe a very large population (Babbie, 1986).

\section{Locale of the Study}

The PNAP program was implemented in the southern Negros Occidental, covering the different municipalities and cities specifically Binalbagan, Himamaylan, Kabankalan, Ilog, Cauayan, Sipalay and Hinoba-an located in the most productive mangrove ecosystems of the southern side of the Negros Island.

\section{> Sample/s and Sampling Technique}

For this study, surveys were done from selected cluster purposeful sampled sub-units. The respondents represented by the PO president served as participants in whom they have direct engagement with the PNAP mangrove $\mathrm{CBC}$ conservation project implemented in southern Occidental Negros Philippines.

\section{$>$ Research Instrument}

Focus group discussion was facilitated to gather data from the respondents concerning the benefits gained with the project.

\section{$>$ Data Analysis}

To answer the stated objectives, descriptive statistics specifically frequency and percentage distribution were used for objectives 1, 2 and 3, while in objective 4, mean was used.

\section{RESULTS AND DISCUSSIONS}

PNAP Phase-1

\begin{tabular}{|c|c|c|}
\hline \multicolumn{2}{|c|}{ PHASE 1 BUDGET DISTRIBUTION } \\
\hline Resource/Habitat & Aquasilviculture & Multi-Species \\
\hline Rehabilitation & & Hatchery \\
\hline$(\mathrm{PhP})$ & $(\mathrm{PhP})$ & $(\mathrm{PhP})$ \\
\hline $1,118,000.00$ & $845,000.00$ & $1,140,000.00$ \\
\hline Total Project Cost: PhP 3,497,000.00
\end{tabular}

Table 1:- Budget Distribution Phase 1 
ISSN No:-2456-2165

\begin{tabular}{|c|c|c|c|c|}
\hline \multicolumn{5}{|c|}{ MANGROVE PLANTING \& DISBURSEMENT REPORT-PHASE 1 (100\% Accomplishment) } \\
\hline Beneficiaries & Area (Ha.) & Propagules (Pcs.) & Payments (PhP) & POs \\
\hline 27 & 7.00 & $52,542.00$ & $341,523.00$ & Nabuswang, Binalbagan \\
\hline 29 & 2.00 & $15,000.00$ & $97,500.00$ & Canmoros, Binalbagan \\
\hline \multirow[t]{2}{*}{23} & 1.00 & $7,500.00$ & $48,750.00$ & Enclaro, Binalbagan \\
\hline & & 958.00 & $6,227.00$ & Enclaro, Binalbagan \\
\hline 79 & 10.0 & $76,000.00$ & $494,000.00$ & Total Binalbagan \\
\hline 36 & 3.33 & $27,000.00$ & $175,500.00$ & Malusay, Himamaylan \\
\hline 45 & 3.33 & $23,000.00$ & $149,500.00$ & Mapait, Himamaylan \\
\hline 28 & 3.33 & $25,000.00$ & $162,500.00$ & Punta Batang, Himamaylan \\
\hline 109 & 10.0 & $75,000.00$ & $487,500.00$ & Total Himamaylan \\
\hline 30 & 5.00 & $15,000.00$ & $97,500.00$ & Caliling, Cauayan \\
\hline 34 & 2.00 & $6,000.00$ & $39,000.00$ & Lina-on, Cauayan \\
\hline 64 & 7.0 & $21,000.00$ & $136,500.00$ & Total Cauayan \\
\hline 252 & 27.0 & $172,000.00$ & $1,118,000.00$ & Grand Total \\
\hline
\end{tabular}

Table 2:- Mangrove Planting and Disbursement Phase 1

Carlos Hilado Memorial State College (CHMSC) accomplished $100 \%$ of the phase 1 of the Philippine National Aquaculture Program (PNAP) of Bureau of Fisheries and Aquatic Resources (BFAR) on resource/habitat rehabilitation, aquasilviculture, and community-based multispecies lying-in hatchery.

The implementation was based on memorandum of agreement between Dr. Drusila Esther E. Bayate, regional director of BFAR-Region VI, and Dr. Renato M. Sorolla, president of CHMSC. It started on July 1, 2012 and ended on June 30, 2013. Dr. Renato M. Sorolla designated Dr. Mario N. Abeto, Mr. Andrew D. Ordonio, Mr. Roger Ray S. Manzano, and Mr. Noel N. Lebrilla to implement the projects.

BFAR provided a total budget of Php3.497M broken down among the following projects: Php1,118,000 for resource/habitat rehabilitation; Php845,000 for aquasilviculture; Php1,140,000 for community-based multi-species hatchery; and Php394,000 for administrative cost.

Coastal habitat rehabilitation targeted the planting of 172,000 mangrove propagules in southern Negros Occidental. Of that, 76,000 propagules were planted in
Binalbagan; 75,000 in Himamaylan City; and 21,000 in Cauayan. A total of P1.118M was paid to 262 fisherfolk beneficiaries. The phase- 1 targeted to plant mangroves in a land area of 27 hectares.

Aquasilviculture is the growing of commercially valuable aquatic organisms beneath healthy mangrove stands without cutting down any tree. The target was to put up 13 aquasilviculture Techno Demo, each Techno Demo has a budget of P65,000. The stocks were milkfish and mudcrab juveniles. It transferred viable fisheries technology to 10 People Organizations (PO's) composed of 274 fisherfolk beneficiaries to augment income. There were 5 Techno Demo in Binalbagan, 2 in Kabankalan City, 1 in Ilog, 2 in Cauayan, and 3 in Hinoba-an.

For crab stock enhancement or reseeding, the community-based multi-species lying-in hatchery annexed to finfish hatchery of CHMSC-Binalbagan stocked, as of last September, a total of 1,284 berried wild bluecrab. Each crab was estimated to produce up to 2 million eggs that were released to the wild. Conservative estimate of crabhatchling survival in natural habitat under natural conditions was $1 \%$. The survival represented the contribution of the project for the beleaguered blue-crab capture fisheries. 
PNAP Phase-2

\begin{tabular}{|c|c|c|c|c|}
\hline \multicolumn{5}{|c|}{ BFAR (PNAP) -CHMSC PROGRAM - PHASE 2 IMPLEMENTATION (100\% Accomplishment) } \\
\hline Beneficiaries & Area (Ha.) & Planted (Pcs.) & Payment (PhP) & Place \\
\hline \multirow[t]{2}{*}{22} & 3.00 & 22,500 & $146,250.00$ & PEARL, Binalbagan \\
\hline & 5.00 & 37,500 & $243,750.00$ & PEARL, Binalbagan \\
\hline 32 & 3.00 & 22,500 & $146,250.00$ & Canmoros, Binalbagan \\
\hline \multirow[t]{2}{*}{28} & 4.00 & 30,125 & $195,812.50$ & Nabuswang, Binalbagan \\
\hline & 1.00 & 7,500 & $48,750.00$ & Nabuswang, Binalbagan \\
\hline 82 & 16.00 & 120,125 & $780,812.50$ & Total Binalbagan \\
\hline 33 & 6.40 & 48,000 & $312,000.00$ & Linaon, Cauayan \\
\hline 36 & 5.00 & 37,500 & $243,750.00$ & Caliling, Cauayan \\
\hline 69 & 11.40 & 85,500 & $555,750.00$ & Total Cauayan \\
\hline 23 & 1.50 & 11,250 & $73,125.00$ & Esmeralda, Hinoba-an \\
\hline 21 & 1.50 & 11,250 & $73,125.00$ & Totong, Hinoba-an \\
\hline 15 & 1.50 & 11,250 & $73,125.00$ & Manalimsim, Hinoba-an \\
\hline 38 & 1.50 & 11,250 & $73,125.00$ & Asia, Hinoba-an \\
\hline 97 & 6.00 & 45,000 & $292,500.00$ & Total Hinoba-an \\
\hline 248 & 33.4 & 250,625 & $1,629,062.50$ & Grand Total \\
\hline
\end{tabular}

Table 3:- Mangrove Planting and Disbursement Phase 2

Presently, the PNAP-Phase-2 with a budget of Php $1,914,062.50$ for resource/habitat rehabilitation has been implemented from July 1, 2013 to June 30, 2014. Coastal habitat rehabilitation targeted the planting of 250,625 mangrove propagules in southern Negros Occidental at Php 6.50/propagule. Of that, 120,125 propagules were planted in Binalbagan; 85,500 in Cauayan and 45,000 in Hinoba-an. A total of Php 1,629,062.5 was paid to 248 fisherfolk beneficiaries, the remaining amount was spent for administrative costs amounting Php 285,000.00. The phase- 2 targeted to plant mangroves in a land area of 33.4 hectares.

\section{Phase-3 and Phase-4}

Presently, the PNAP-Phase 3 and 4 with a budget of Php 778, 750.00 and Php 3,959,000, a total of Php $4,737,750.00$ for resource/habitat rehabilitation has been both implemented from July 1, 2015 to June 2016 in
Municipalities of Binalbagan, Ilog, Cauayan, Hinoba-an and Cities of Kabankalan and Sipalay. Coastal habitat rehabilitation targeted the planting of 524,500 mangrove propagules in southern Negros Occidental at Php 7.00 /propagule. Of that, 524,500 target, 90,000 propagules were planted in Binalbagan; 22,500 in Ilog; 30,000 in Kabankalan; 187,000 in Cauayan; 30,000 in Sipalay and 135,000 in Hinoba-an. The CHMSC-Binalbagan was initially paid Php 2,098,000.00 for 673 fisherfolk planters beneficiaries at Php 4.00/propagule initial payment and remaining payment of $\mathrm{Php} \mathrm{3.00/propagule} \mathrm{for} \mathrm{survival}$ amounting a total of Php 1,577,700.00. The phase 3 and 4 targeted to plant mangroves in a land area of 70 hectares. The two phases of PNAP was on-going project which will be ended on June 2016. The administrative cost for two (2) phases of program was Php 270,000.00 for phase 3 and Php 234,000.00 for phase 4, a total of Php 504,000.00. 
Implementation of PNAP Project Phase 1, Phase 2, Phase 3 and Phase 4

\begin{tabular}{|c|c|c|}
\hline Statements & Mean & Interpretation \\
\hline 1. Project responsiveness to the needs of beneficiaries & 4.72 & Best (napakahusay) \\
\hline 2. Timely release of funding for the project & 4.65 & Best (napakahusay) \\
\hline 3. Harmonious relation of implementers with beneficiaries & 4.81 & Best (napakahusay) \\
\hline 4. Project contribution to the improvement of living & 4.63 & Best (napakahusay) \\
\hline 5. Transparency in all aspects of project implementation & 4.58 & Best (napakahusay) \\
\hline Total & $\mathbf{4 . 6 3}$ & Best (napakahusay) \\
\hline
\end{tabular}

Note: 220 total respondents participated in the survey

Table 4:- Beneficiary Satisfaction Survey (July 2012 - June 2016)

The 220 randomly selected PNAP beneficiaries rated "Best (Napakahusay)" in all aspects of program implementation in which the harmonious relation of implementers with beneficiaries gained the highest rating, followed by project responsiveness to the needs of beneficiaries, timely release of funding for the project and project contribution to the improvement of living while transparency in all aspects of project implementation rated the lowest. The five (5) aspects of program implementations were important factors of service delivery to the community and the response of beneficiaries were a heart touching to note that they were really appreciate the efforts made by CHMSC-Binalbagan as accountable implementer.

\section{CONCLUSIONS}

The Bureau of Fisheries and Aquatic Resources (BFAR)-Philippine National Aquasilvilculture Program (PNAP) downloaded to CHMSC-Binalbagan a total of Php $10,148,812.50$ for the four (4) phases of project implementations in southern Negros Occidental.

Of the amount, Php 6,422,762.5 went to resource rehabilitation (mangrove planting); Php 845,000.00 for Aquasilviculture; Php 1,140,000.00 for Multi-species hatchery and Php 1,741,050.00 for administrative costs.

The total 1,271,400 propagules were planted by 673 direct fisherfolk beneficiaries in a total of 130.4 hectares. From the total 978,000 propagules have been paid and 293,400 were added by the beneficiaries as buffer or insurance. Planting survival reached $90 \%$. The mangroves, as expected, will provide a variety of fishes and molluscs to sustain the livelihood of fisherfolks and help in food security in fisheries.

There were 274 beneficiaries for Aquasilviculture. The project was meant to demonstrate the technical feasibility of growing fish and crustaceans beneath mangrove stands without cutting down the trees. In Aquasilviculture, the beneficiaries grew bangus and mudcrab and sell them to augment their income.

The 1,284 wild berried bluecrab were stocked in the community based muti-species hatchery for release of their clutch of eggs back to wild. Each stocked crab was estimated to produce up to 2 million eggs. A $1 \%$ survival in a natural habitat represents a conservative estimate of the contribution of the project to the beleaguered blue-crab fishery in the area. Aside from stocking crabs, the hatchery produced also hybrid and fast growing tilapia fingerlings that were sold to support local tilapia growers.

The municipal and city mayors have been appreciating the BFAR-PNAP implementation; for them, the projects can be trusted to help their constituents. The projects have never been reneged ever since to pay all direct beneficiaries.

The contribution of the projects to fisherfolks to ease their financial woes may be represented by appreciation of a beneficiary of the amount he/she signed in payroll: in all his/her life, it was the biggest single amount he/she ever received. The amount of Php 1,700.00.

\section{RECOMMENDATIONS}

The Government should continue to provide support and funding to the Extension and Community Services which focuses on ENVIRONMENTAL REHABILITATION, CONSERVATION and PROTECTION, INCOME GENERATING and COMMUNITY DEVELOPMENT of the Academe specifically the CHMSC system for more realistic, sustainable and responsible services and program delivery to combat the needs of COMMUNITY under the marginalized sector of the country.

\section{REFERENCES}

[1]. Alongi, D.M. 2002. Present state and future of the world's mangrove forests. Environmental Conservation, 29, 331-349.

[2]. Alongi, D.M. (2009) Introduction in the energetics of mangrove forests. Springer Science and Business Media BV, New York.

[3]. Andradi-Brown, DA, C Howe, GM Mace, and AT Knight. 2013. Do mangrove forest restoration or rehabilitation activities return biodiversity to preimpact levels? Environmental Evidence 2:20 
[4]. Barbier EB, Hacker SD, Kennedy C, Koch EW, Stier AC, Silliman BR: The value ofestuarine and coastal ecosystem services. Ecol Monogr 2011, 81:169-193.

[5]. Blasco, F., Aizpuru, M. \& Gers, C. (2001) Depletion of the mangroves of Continental Asia. Wetlands Ecology and Management,9, 245-256.

[6]. Giri, C. E. Ochieng, L.L. Tieszen, Z. Zhu, A. Singh, T. Loveland, J. Masek, and N. Duke. 2010. Status and distribution of mangrove forests of the world using earth observation satellite data. Global Ecology and Biogeography, (Global Ecol. Biogeogr.) (2010)

[7]. Giri, C., Pengra, B., Zhu, Z., Singh, A. \& Tieszen, L. 2007. Monitoring mangrove forest dynamics of the sundarbans in Bangladesh and India using multi-temporal satellite data from 1973-2000. Esturine, Coastal and Shelf Science, 73, 1-2,91100.

[8]. Giri, C., Z Zhu, LL Tieszen, A Singh, S Gillette, and JA Kelmelis. 2008. Mangrove forest distributions and dynamics (1975-2005) of the tsunami-affected region of Asia. Journal of Biogeography, 35, 519-528.

[9]. Gunawardena M, JS Rowan. 2005. Economic valuation of a mangrove ecosystem threatened by shrimp aquaculture in Sri Lanka. Environ Manage, 36:535-550.

[10]. Latiff, A. 2012. Conservation Strategies For Endangered Mangrove Swamp Forests In Malaysia. Pak. J. Bot., 44: 27-36,

[11]. Mumby PJ, A. Hastings. 2008. The impact of ecosystem connectivity on coral reef resilience. J Appl Ecol, 45:854-862.

[12]. Primavera JH. 1997. Socio-economic impacts of shrimp culture. Aquac Research, 28:815-827. 